\title{
Study on Eco-tourism Exploitation Model of Nature Reserves in China
}

\author{
Zengxue Lin \\ Ginlin Tourism University, Guangxi, Guilin, 541006, China
}

\begin{abstract}
Ecotourism is an important form of tourism development today and the nature reserves provide an excellent ecological background for ecotourism. This paper analyzes the present situation of ecotourism in nature reserve of China and discusses the development model of ecotourism in nature reserve.
\end{abstract}

Keywords: eco-tourism, exploitation model, nature reserves

\section{Introduction}

Ecotourism is the fastest-growing form of tourism in today's tourism industry. It is based on human reflections on the relationship between tourism and the environment. It is the embodiment of eco-environmental ethics and sustainable development in tourism. Ecotourism is a tourism activity that allows tourists to enjoy, explore, enjoy and preserve nature in relatively natural areas (including humanities), raise funds for protected areas, and provide employment opportunities for local communities to participate in decision-making to achieve tourism objectives to sustainable development. Although the rise of ecotourism is the result of the enhancement of human environmental awareness and the sustainable development of tourism destination, it is also the result of the further expansion of global tourism market. The increase of tourism demand, especially natural tourism, makes the remote, disturbed areas are developed as new tourist destinations. Therefore, eco-tourism is also a double-edged sword, both to the protected area has brought opportunities, but also full of challenges. The relationship between ecotourism and nature conservation and community development; how to coordinate the relationship among ecotourism development 
and management in ecotourism in order to minimize the negative impact of ecotourism so as to maximize the comprehensive benefits, Are urgently needed to solve the problem.

At present, there are two kinds of ecotourism research in nature reserve in China, one is the case study of development and planning, but most of these researches are empirical and the theoretical basis is not enough. The planning is mostly hanging on the wall, the majority of the research and development cannot really refer to the nature reserve. The other kind of research is the theoretical research on the ecotourism development of the nature reserve. The majority of them are the principles of the development of nature protection ecotourism, the problems to be noticed and the macroscopic countermeasures. The lack of analysis and summary of actual cases, the lack of realistic basis and the proposed countermeasures are also lack of targeted, practical or application of little value.

Therefore, on the basis of analyzing the concept and principle of ecotourism, the study on the relationship between nature reserve ecotourism and nature conservation and community development is helpful to clarify the value judgment of human being, and provide the scientific basis for human moral ethics and behaviour criterion. The study on the development and planning of ecotourism in nature reserves will provide the theoretical basis for the utilization of ecotourism resources, tourism product development and facilities planning and design; the restoration and improvement of the ecological environment of the protected areas, the improvement of the living standards of the local residents, coordinated sustainable development has important practical significance. The study on ecotourism management of nature reserves has important guiding significance for strengthening the management of tourists in ecotourism, the management of ecotourism enterprises, community participation and community management, and the reform of ecotourism management system.

\section{The necessity of tourism development in nature reserves}

Eco-tourism, also known as green tourism, is the international community in the late 80 's a new way of tourism. Compared with all kinds of traditional tourism, eco-tourism has the following characteristics: (1) high taste. Tourists generally higher cultural literacy, mostly for the beauty and mystery of nature attracted to view the beauty of nature, access to natural ecological knowledge and knowledge of human history mainly; (2) strong planning. Tourism operators are generally after the feasibility of ecological and environmental feasibility studies, under the guidance of scientific planning and development and construction; tourists are generally pre-check after the understanding of the strict organization and management under the purpose of the purpose of the tour, in order to obtain the nature Of knowledge, explore the mysteries of the natural ecology; (3) nature. Tourists and tour operators are stressed that highlight the natural qualities, visit the tour to the natural ecological qualities as the centre, the need for tourism 
facilities is simple; Non-loss of environmental resources use, is a pollution-free, no damage, strong ecological security tour.

China's various types of protected areas have reached more than 750, an area of $50 \times 104 \mathrm{Km} 2$ or more, accounting for more than $5 \%$ of land area. If this part of the land as a closed human activities "closed area", will result in huge resources "idle"; China's many natural beauty and special cultural and historical landscape and more concentrated in various types of protected areas, if not actively develop If we do not develop the resources of the protected areas and develop the local economy, it will mean that the state is in debt, and the development of the national economy will be impaired. In the meantime, the development of the tourism industry will be seriously affected by the tourism resources of these regions. People are poor, not only the cause of natural protection is difficult to sustainable development, the people of these regions to get rid of poverty is also difficult to achieve as soon as possible.

It is of great significance to actively develop environmental resources and develop eco-tourism in the reserve: (1) Raising a large amount of funds for the protected areas to maintain the normal construction and management of the protected areas and promote the sustainable development of nature protection; (3) give full play to the protected areas in the cultural and educational, scientific investigation, health care, environmental education, tourism should be on tourism, tourism, tourism, tourism, tourism, tourism and other cultural and educational activities; Function, and enhance public awareness of environmental protection; (4) can improve the relationship between protected areas and local residents, so that it truly become the cause of nature protection advocates, supporters and participants.

\section{The problems in eco-tourism of nature reserve}

\subsection{Extensive development and blind use of the eco-tourism resources}

Many protected areas in the development of eco-tourism resources, the lack of indepth investigation and comprehensive scientific demonstration, assessment and planning, individual protected areas and even in the background investigation of resources has not yet completed, the protection of the characteristics and laws are not fully grasp of the case to carry out eco-tourism. In some mountain nature reserves, regardless of the ecological fragmentation of the ecosystem or the risk of islanding, blindly road or cableway, not only caused by changes in animal and plant population structure, but also dependent on the corridor landscape life reproduction of wildlife Resulting in barriers to genetic communication, viability and restrictions in the field of activities.

\subsection{Lack of scientific management}

The phenomenon of multi-management in protected areas has seriously affected the scientific management of ecotourism in protected areas. For example, the 
management of scenic areas is under the management of the Ministry of Forestry, the forest parks are owned by the Ministry of Forestry and the nature reserves are integrated by EPB. Problem, the natural environment has become one of the victims. The mutual exclusion and conflict between ecotourism area, local community and government, protected area authority and management department is more than cooperation and coordination. The ecotourism managers lack the comprehensive understanding of the connotation, guidelines and science and technology of ecotourism. Most of the tourism activities remain in the traditional mode of development and management, and the publicity of ecological environmental protection knowledge is not enough.

\subsection{Lack of effective oversight mechanisms}

Lack of evaluation of environmental carrying capacity before development, lack of environmental impact monitoring in eco-tourism areas, and lack of effective feedback mechanism, cannot promote the sustainable development of ecotourism areas. As the eco-tourism areas are mostly ecologically fragile and sensitive areas, if the environmental protection measures are weak, it is likely to cause ecological degradation. According to the survey, only $16 \%$ of the protected areas in which ecotourism has been carried out have regular environmental monitoring, and some of the protected areas do not even have the necessary monitoring instruments.

\section{The eco-tourism development model of nature reserve}

With the guidance of sustainable development strategy and system theory, the author puts forward a new model of ecotourism development in nature reserve, which is "protection, development and management", with reference to the successful experience of ecotourism development in the national and international protected areas.

\subsection{Protection systems engineering}

Protection is the main purpose and starting point of the establishment of nature reserves. Therefore, the protection system engineering is the nature protection area protection development conformity pattern three systems 12 projects in the primary system engineering. According to the characteristics of resources and environmental conditions of the nature reserve, the protection engineering system mainly includes biodiversity conservation project, geological heritage protection project, humanistic ecological protection project and environmental testing project. The protection of nature reserves should not only emphasize the protection of their biological diversity, but also emphasize the protection of geological heritage. The geological relic resources are the important resources of nature reserves, and should be protected and exploited. Protected areas, especially in ethnic minority protected areas of the community, the protection of human 
ecology cannot be ignored. Environmental monitoring can play an important role in monitoring. Eco-tourism is a high-tech industries, should rely on science and technology to establish a sound environmental monitoring system.

\subsection{Development systems engineering}

Development is not an end in itself, but a means and a means of achieving development. The purpose of eco-tourism development in nature reserves is not to achieve economic benefits alone, but to better protect and develop them. Development is a complex and complex systems engineering. In the process of the development of the system engineering, the scientific planning is the leading, the product, the market and the facility construction is the most basic and the most important development in the nature protection ecotourism development, is the development chain which realizes the resource - product - market - benefit transformation. Therefore, the development of systems, including scientific planning projects, product development projects, market development projects and facilities construction project four key.

\subsection{Management Systems Engineering}

Capacity building, community co-management, environmental education and management innovation play an important role in the development of ecotourism in nature reserves. Among them, the problem of capacity building in recent years in different areas have been more widely used, has become an important jargon or terminology. Capacity-building projects in nature reserves can include the ability to improve resource management, improve the capacity of scientific research and monitoring, improve self-development capacity, improve community co-management capacity and improve the ability to integrate with international standards.

\section{Conclusion}

The rise of ecotourism is the result of the enhancement of human environmental awareness and the sustainable development of tourism destination. From another point of view, it is also the result of the further expansion of global tourism market. The increase of tourism demand, especially natural tourism, makes the remote, disturbed areas are developed as new tourist destinations. Ecotourism has brought new opportunities for the development of nature reserves in China. However, ecotourism is also a double-edged sword. At present, ecotourism in China's nature reserves has many problems and needs to be studied in depth.

\section{Acknowledgements}

The research work was supported by Guangxi high-level innovation team in Colleges and universities (training unit). 


\section{References}

[1] Lin Sheng. Discussion on the Relationship between Resource Protection and Ecological Tourism in Wuyishan Nature Reserve. Ecological economy, 55(12), pp.68-70, 2011

[2] Discussion on Eco - tourism Development of Nature Reserves in China. Human Geography, 8 (5), pp.87- 91, 2013

[3] Development Strategies of Eco - tourism in Nature Reserves of China. Journal of Jiaozuo Teachers College, 12(10), pp. 18- 20, 2012

[4] Sun G N. Study on the development model of ecotourism in nature reserves in China. Resources Science, 9(6), pp.58- 61, 2011

[5] Huang Xiaoling. Preliminary Study on Tourism Product Development of Wuyishan Nature Reserve, Problems of Forestry Economy 8(4), pp.85-87, 2014 